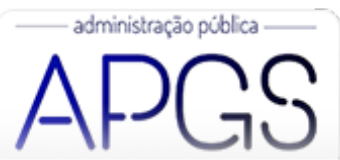

Administração Pública e Gestão Social

ISSN: 2175-5787

apgs@ufv.br

Universidade Federal de Viçosa

Brasil

\title{
Dinâmicas Relacionais na Implementação de Políticas Públicas: Análise do Programa Minha Casa, Minha Vida - Entidades
}

Euclydes, Fillipe Maciel; Ramos Silveira, Suely de Fátima; Teixeira de Campos, Ana Paula; Tavares, Bruno Dinâmicas Relacionais na Implementação de Políticas Públicas: Análise do Programa Minha Casa, Minha Vida Entidades

Administração Pública e Gestão Social, vol. 14, núm. 1, 2022

Universidade Federal de Viçosa, Brasil

Disponible en: https://www.redalyc.org/articulo.oa?id=351569604006

\section{(c) (1) (9)}

Esta obra está bajo una Licencia Creative Commons Atribución-NoComercial-SinDerivar 4.0 Internacional. 


\section{Dinâmicas Relacionais na Implementação de Políticas Públicas: Análise do Programa Minha Casa, Minha Vida - Entidades

\section{Resumo:}

Objetivo da Pesquisa: Investigar a implementação do Programa Minha Casa, Minha Vida - Entidades, em Conselheiro LafaieteMG, a partir das interações que emergem desse processo.

Enquadramento Teórico: As perspectivas da Policy Network, considerada enquanto método e abordagem analítica, forneceram o quadro orientado à compreensão das dinâmicas relacionais.

Metodologia: A coleta de dados foi realizada por meio de análises documentais e de entrevistas semiestruturadas; o tratamento dos dados, a partir da Análise de Conteúdo e da Análise de Redes Sociais.

Resultados: Foi observado como as alterações nas naturezas das relações e a reconfigurações das redes foram condicionadas a aspectos do ambiente no qual a política pública é implementada.

Originalidade: $\mathrm{O}$ trabalho apresenta formas alternativas de emprego da Policy Network, sendo a abordagem relacional mista uma estratégia capaz de desvelar a dimensão político-contextual em um fenômeno que é subjetivo, variável e contingente.

Contribuições Teóricas e Práticas: Evidenciou-se a necessidade de se compreender as dimensões históricas, político-institucionais e sociais que conformam a execução das políticas públicas. O entendimento desses elementos fornece subsídios para análises mais condizentes com a realidade, confirmando a fragilidade de compreender a implementação como um simples output das etapas de agenda e formulação.

PalaVras-chaVe: Política Pública, Implementação, Policy Network , Habitação.

\section{Abstract:}

Research Aim: This study has investigated the implementation of the Program Minha Casa, Minha Vida -Entidades, in Conselheiro Lafaiete-MG, based on the emerging interactions from this process.

Teoretical Framework: The Policy Network has provided an analytical framework for understanding relational dynamics. Methodology: Data was collected through documents analysis and semi-structured interviews. Data was processed based on Content Analysis and Social Network Analysis.

Results: we have observed how changes in the natures of network relations and reconfigurations are conditioned by aspects that are shaped by the environment in which public policy is implemented. 
Originality: The work presents alternative ways of using the Policy Network, and the mixed relational approach is a strategy capable of unveiling the political-contextual dimension in a phenomenon that is subjective, variable, and contingent.

Theoretical and Practical Contributions: The necessity to understand the historical, political and social (politics) dimensions in this process was also evident. The comprehension of these dimensions provides support for analyzes more consistent with reality, confirming the fragility of the implementation process understanding as a simple output of agenda and formulation stages.

KEYWORDS: Public Policy, Implementation, Policy Network, Housing.

\section{RESUMEN:}

Objetivo de la Investigación: Este estudio tuvo como objetivo investigar la implementación del Programa "Minha Casa, Minha Vida - Entidades", en Conselheiro Lafaiete-MG, a partir de las interacciones que surgen de este proceso.

Marco teórico: Las perspectivas de la Policy Network, consideradas como un método y enfoque analítico, proporcionaron el marco para comprender las dinámicas relacionales.

Metodología: La recopilación de datos se realizó a través de análisis documentales y entrevistas semiestructuradas, y el tratamiento de datos de Análisis de contenido y Análisis de redes sociales.

Resultados: Se observó cómo los cambios en la naturaleza de las relaciones de red y las reconfiguraciones están condicionados por aspectos que son moldeados por el entorno en el que se implementan las políticas públicas

Originalidad: El trabajo presenta formas alternativas de utilizar la Policy Network, y el enfoque relacional mixto es una estrategia capaz de desvelar la dimensión política-contextuale en un fenómeno que es subjetivo, variable y contingente.

Aportes Teóricos y Práctica: Fue importante también comprender las dimensiones históricas, políticas y sociales que existen en la ejecución de una política pública. Comprender estos elementos proporciona información para un análisis más basado en la realidad, lo que confirma la fragilidad de comprender el proceso de implementación como un resultado simple de la agenda y los pasos de formulación.

Palabras Clave: Política Pública, Implementación, Policy Network, Vivienda.

\section{INTRODUÇÃo}

No domínio de políticas públicas (policy domain) habitacionais, o Programa Minha Casa, Minha Vida (PMCMV) refere-se a maior intervenção estatal da história brasileira (Amore, Shimbo, \& Rufino, 2015). Estatísticas oficiais exemplificam sua importância. Em 11 anos de execução (2009-2020), o PMCMV contratou mais de 6 milhões de unidades habitacionais, estando presente em 5.391 municípios do país (Brasil, 2021). Foram investidos, para tanto, $\mathrm{R} \$ 557$ bilhões de reais (Brasil, 2021).

Dada a relevância do Programa e de seu tempo de operação, a multidimensionalidade dos efeitos e impactos dessa intervenção foi amplamente discutida na literatura. Obras como as organizadas por Lago (2012), Cardoso (2013) e Amore et al. (2015), além de relatórios-síntese como os de Balbim, Krause e Lima (2015) e de Brasil (2020), evidenciaram aspectos relacionados ao planejamento urbano, aos impactos sobre as cidades e as famílias contempladas, à segregação socioespacial dos empreendimentos, bem como seus efeitos sobre a criação de emprego e renda. Do ponto de vista do campo de públicas, registram-se igualmente importantes pesquisas ressaltando as mudanças institucionais das políticas (Zapelini, Lima, \& Guedes, 2017), os aspectos locais da operação do PMCMV (Moreira, Silveira, \& Euclydes, 2018) e questões quanto à avaliação da intervenção (Moreira \& Silveira, 2015).

A magnitude do PMCMV se deve também ao fato de ser um "Programa-Plano" sob o qual foram criados diferentes fundos de financiamento e modalidades de operação (Amore et al., 2015). O Programa foi inicialmente instituído em três Faixas, conforme a renda das famílias beneficiárias e a respectiva fonte de financiamento. Relevante para este estudo, a Faixa 1, que é a de interesse social, apresenta diferentes modalidades. A principal delas é o Fundo de Arrendamento Residencial (FAR), na qual ocorre operações diretas entre construtoras e agentes públicos operadores (Moreira et al., 2018). Existe também a modalidade Entidades (PMCMV-E), na qual organizações da sociedade civil assumem papel central na implementação do Programa (Lago, 2012). O PMCMV-E se baseia em ideais de autogestão ${ }^{[\mathrm{i}]}$ habitacional e possui dinâmicas e características específicas (Lago, 2012; Jesus, 2016). Neste estudo, tem-se como foco a implementação 
da modalidade Entidades, que é materializada a partir da interação entre um variado conjunto de atores públicos e não públicos especificados no normativos (leis, decretos e instruções normativas). Inicialmente, os atores formalmente indicados são: Ministério das Cidades (MCidades), Caixa Econômica Federal (CEF), Entidade Organizadora (EO), Secretaria Nacional de Habitação, Beneficiários e Poderes Públicos Municipal e Estadual (Brasil, 2013).

Embora exista relevante estoque de análises acerca de questões institucionais, espaciais, econômicas, financeiras e sociais sobre o PMCMV (Lago, 2012; Cardoso, 2013; Amore et al., 2015; Balbim et al., 2015), tem-se, ainda, lacunas quanto a investigações que busquem compreender dimensões influenciadoras do seu processo de implementação. Relacionado a esse tema, registram-se trabalhos sobre como a dinâmica de execução do PMCMV-E ocorre em nível federal (Viana, 2019) e como o arranjo do PMCMV, principalmente investigando a modalidade FAR, possui margem de adaptação em nível local conforme as diferenças entre atores e instituições (Moreira et al., 2018; Lavalle, Rodrigues, \& Guicheney, 2019). Por outro lado, ainda são incipientes as pesquisas sobre como o processo de implementação é condicionado pela natureza e a configuração das interações sociais e contextuais, sendo esse o objetivo deste estudo.

Para atingir tal propósito, optou-se pelo emprego da estratégia do estudo de caso único, recomendada para questóes complexas, situadas e problemáticas (Stake, 2000). O estudo de caso é do tipo instrumental (Stake, 2000), isto é, sua escolha é baseada na utilidade de analisar um determinado fenômeno para entendimento de um cenário teórico-empírico mais aprofundado. Neste trabalho, ele é empregado para analisar como a implementação de uma política pública complexa, composta por múltiplos atores públicos e não públicos, se desenvolve com base em seu ambiente local e conforme as interações entre agentes. Contexto/ambiente é interpretado a partir dos conceitos de Pollitt (2013) e Tilly e Goodin (2006), referindo-se a distintos planos (histórico, político e econômico) e instituições (regras do jogo da política pública) que se intercruzam e conformam o cenário no qual ocorrerá as interações e disputas entre atores, interesses e ideias na materialização de políticas públicas.

Como delimitação espacial, optou-se por investigar a implementação da modalidade em Conselheiro Lafaiete - Minas Gerais (MG), levando em consideração o fato de essa cidade ter recebido o maior aporte de recursos no âmbito da modalidade em MG (10,6\% do total investido no estado) (Brasil, 2016); abrigar a primeira e única operação executada do PMCMV-E no âmbito da Gerência Executiva de Habitação de Belo Horizonte (GIHAB-BH), que possui sob sua jurisdição 62 municípios e é responsável pela aprovação dos projetos na modalidade; e ser o único contrato firmado na Faixa I do PMCMV no município, mesmo tendo a modalidade Entidades um caráter secundário no Programa (Lago, 2012). Esse conjunto de elementos sinalizam para a unicidade do caso escolhido, sendo instrumentalmente relevante para atingir os objetivos propostos e a contribuição do estudo (Stake, 2000).

O arcabouço teórico escolhido toma como base a discussão sobre a "Policy Network", que analisa a "configuração dos atores institucionais e sociais envolvidos em um processo de formulação e /ou implementação de uma política pública” (Clivaz, 2001, p. 5). Ao enfatizar aspectos políticos-contextuais, a Policy Network permite observar o formato da política pública como a expressão do resultado de interações, disputas e acordos ocorridos nesse processo (Subirats, Knowepfel, Larrue, \& Varonne, 2012; Marques, 2019). Dessa forma, é exposto o "jogo da implementação" (a politics), no qual estão implícitos esses enfrentamentos, ambiguidades e negociações (Abers, 2015, Hupe \& Hill, 2016; Pires, Lotta, \& Oliveira, 2018). Na segunda seção deste trabalho, esses conceitos são aprofundados.

Realizada a apresentação do tema e de sua importância, este artigo conta com mais quatro seções além desta introdução. A seguir, apresenta-se o referencial com as abordagens teóricas orientadoras desta pesquisa. Posteriormente, tem-se os procedimentos metodológicos. Os resultados e discussões estão dispostos na seção 5, encerrando-se, em seguida, com a conclusão. 


\section{A Implementação de Políticas Públicas e sua Dimensão Político-Contextual}

À medida que se compreende que o sucesso de uma política pública está diretamente relacionado à forma como ela é colocada em prática, investigar o processo da implementação de políticas públicas tem assumido cada vez mais relevância (Subirats et al., 2012; Hill \& Hupe, 2014; Lotta, 2019). Não obstante, parte da literatura permanece relegando a implementação à condição de "elo perdido" no processo de políticas públicas (Rua, 2012). Esse fato, para Lindblom (1981), está baseado na inadequada interpretação sobre o policy process, uma vez que esse processo é entrelaçado e contínuo, o que evidencia a fragilidade do raciocínio que separa, normativamente, política e administração (Pires et al., 2018).

Ao registrarem a presença de aspectos políticos e contingenciais no processo de implementação, autores seminais do campo como Pressman e Wildavisky, em 1973, Gunn, em 1978, e Sabatier e Mazmanian, em 1979, começaram a desafiar a tradicional visão da implementação como um processo prescritivo que deve ser habilmente controlado (Lotta, 2019). Até então, a execução de uma política pública era vista como estática, pré-moldada e fechada a contingências e a adaptações externas, e que sua eficiência dependia de um efetivo controle e de recursos sociotécnicos adequados para que os produtos gerados fossem iguais aos inicialmente previstos. Dessa concepção, depreende-se que a implementação tem um caráter racional, em que seu resultado só não será atingido caso os planos estejam equivocados (Lotta, 2019).

A dualidade entre problemas sociotécnicos e questões políticos-contextuais, mesmo se tratando de um debate reatualizado no campo (Hupe \& Hill, 2016), continua a repercutir na literatura de políticas públicas, reaparecendo, inclusive, em interpretações herméticas sobre o Ciclo de Políticas Públicas (Hill \& Hupe, 2014). Segundo Hupe e Hill (2016), a essência tecnocrática persiste com o entendimento do processo de implementação como um simples output das etapas de agenda e formulação, nas quais dimensões de ambiguidade e conflito (politics) são minimizadas ou desconsideradas. Não obstante reconhecerem a relevância das pesquisas que se dedicam à análise dos problemas sociotécnicos, Hupe e Hill (2016) pontuam que essas investigações não devem ser feitas às custas de uma lente de análise que desconsidere uma relação tão importante como entre a implementação e seu ambiente.

Uma possibilidade analítica para se contornar essa dualidade entre prescrição e contingência, é a utilização da abordagem relacional, a qual, conforme Subirats et al. (2012), é a mais indicada para capturar a politcs presente no processo de implementação, ou seja, capturar toda a riqueza dos atores, seus intercâmbios, negociações e pressões. Neste trabalho, como forma de evidenciar as relações que estruturam, formal e informalmente, a implementação do PMCMV-E e os conflitos e acordos inerentes a elas, optou-se por empregar o arcabouço analítico da Policy Network, o qual possibilita compreender como o formato assumido pela política pública está associado às interações sociais que emergem desse processo.

\section{Policy Network e a Perspectiva Relacional}

A variedade de definições sobre a Policy Network é refletida nas diferentes tentativas de sistematizações sobre o tema (Dowding, 1995; Börzel, 1998; Klijn, 2014). De forma geral, essas pesquisas ora observam a Policy Network como metáfora, ora como método ou, ainda, como uma forma específica de governança. Dada sua importância, as três tradições de pesquisa são brevemente descritas.

Difundida a partir da década de 1970 na ciência política, a maior parte dos estudos que investigam a influência de atores em torno do policy process utilizam a noção de redes como metáfora, empregando métodos qualitativos para tanto. Para Downding (1995), a própria origem do termo Policy Network é essencialmente metafórica, visto que as relações são apresentadas de forma representativa, embora não sejam, por isso, menos úteis. Os estudos desse grupo se detêm mais no conteúdo dessas interações, isto é, em como ocorre o intercâmbio material e imaterial das trocas, do que nas estruturas relacionais quantificáveis. Juntamente com a representação simbólica, parte desses estudos utilizam tipologias para classificar as redes. 
Como exemplo, citam-se conceitos criados como subsistemas de políticas públicas (policy subsystem) (Sabatier \& Weible, 2007), comunidades de políticas públicas (policy communities) (Miller \& Demir, 2007) e redes temáticas (issue networks) (Heclo, 1978).

Uma segunda tradição de pesquisas emergiu no fim da década de 1980 e início de 1990, objetivando encontrar relações sistemáticas entre estruturas relacionais e processos de políticas públicas (Schneider, 2013). Baseado na aplicação da análise de redes sociais (ARS), esse grupo analisa as interações entre atores a partir de indicadores quantitativos como coesão, equivalência estrutural, densidade, representação espacial e centralidade (Scott, 2009). Questões como assimetria das relações e dependência entre atores, são analisadas tendo em vista a posição dos agentes em uma estrutura. De acordo com Leifeld (2007), se inicialmente as publicações sobre Policy Network empregavam preferencialmente a noção de redes de forma metafórica, a utilização da metodologia quantitativa tem sido muito difundida. Ao fazer uma análise de citações nos últimos 30 anos, o autor registrou dezenas de estudos que utilizaram a análise de redes sociais para a compreensão das estruturas relacionais presentes nas mais diversas políticas.

Ligado mais à tradição da administração pública, um terceiro grupo de pesquisas centra-se nas discussões acerca das novas formas de governança, isto é, a construção de arranjos de gestão nos quais as divisas entre setor público e privado têm diminuído (Stoker, 1998). Em geral, essas articulações se caracterizam por seu aspecto fragmentado, em que atores estatais e não estatais devem movimentar recursos, em diferentes níveis de governo, para a coordenação e produção de políticas públicas (Stoker, 1998; Marques, 2016). Alguns autores pontuam o elemento não hierárquico como inovação desse tipo de estrutura (Börzel, 1998, Klijn, 1998), o que, no entanto, não é consenso no campo (Stoker, 1998; Marques, 2016).

$\mathrm{Na}$ Figura 1 são sintetizadas as três principais perspectivas descritas.

Figura 1: Principais tradições da Policy Network e suas características

\begin{tabular}{|c|c|c|c|}
\hline & $\begin{array}{l}\text { Redes como } \\
\text { Metáfora }\end{array}$ & $\begin{array}{l}\text { Redes como } \\
\text { Método }\end{array}$ & Redes de Governança \\
\hline História & $\begin{array}{l}\text { Têm inicio na } \\
\text { ciência política, em } \\
1970 \text {, ao observar } \\
\text { os efeitos das } \\
\text { relações na tomada } \\
\text { de decisão e no } \\
\text { estabelecimento de } \\
\text { políticas }\end{array}$ & $\begin{array}{l}\text { Têm início na } \\
\text { ciência política em } \\
1980 \text { ao empregar } \\
\text { a teoria dos grafos } \\
\text { para encontrar } \\
\text { relações entre } \\
\text { estruturas } \\
\text { interacionais e } \\
\text { resultado }\end{array}$ & $\begin{array}{l}\text { Têm inicio em } 1970 \text { com } \\
\text { trabalhos sobre relações } \\
\text { inter-governamentais e } \\
\text { continuam com a } \\
\text { análise de novas formas } \\
\text { de governança e seus } \\
\text { efeitos sobre a gestão }\end{array}$ \\
\hline Foco Analítico & $\begin{array}{l}\text { No conteúdo das } \\
\text { interaçōes, } \\
\text { observando como } \\
\text { essas diferenciam } \\
\text { os variados } \\
\text { processos políticos }\end{array}$ & $\begin{array}{l}\text { No impacto das } \\
\text { estruturas } \\
\text { relacionais na rede } \\
\text { de políticas }\end{array}$ & $\begin{array}{l}\text { Nas estratégias que } \\
\text { visam melhorar a gestão } \\
\text { em rede, de forma a } \\
\text { produzir resultados } \\
\text { coletivos mais efetivos }\end{array}$ \\
\hline $\begin{array}{l}\text { Principais } \\
\text { Questőes }\end{array}$ & $\begin{array}{l}\text { Quais são os } \\
\text { interesses e } \\
\text { influências dos } \\
\text { atores? Quais são } \\
\text { os efeitos sobre a } \\
\text { tomada de decisão? }\end{array}$ & $\begin{array}{l}\text { Com quem } \\
\text { costuma } \\
\text { trabalhar? Qual a } \\
\text { natureza deste } \\
\text { trabalho? }\end{array}$ & $\begin{array}{l}\text { Como gerenciar redes de } \\
\text { governança? Como } \\
\text { organizá-las e } \\
\text { conectá-las a } \\
\text { instituiçóes } \\
\text { tradicionais? }\end{array}$ \\
\hline $\begin{array}{l}\text { Abordagem } \\
\text { Metodológica }\end{array}$ & $\begin{array}{l}\text { Qualitativa: } \\
\text { Empregam } \\
\text { entrevistas em na } \\
\text { coleta de dados e } \\
\text { utilizam a Análise } \\
\text { de Conteúdoe } \\
\text { Discurso }\end{array}$ & $\begin{array}{l}\text { Quantitativa: } \\
\text { Empregam } \\
\text { questionários na } \\
\text { coleta de dados e } \\
\text { utilizam a Análise } \\
\text { de Rede Social } \\
\text { (ARS) }\end{array}$ & Métodos Mistos \\
\hline
\end{tabular}


Não obstante as diferentes tradições serem originárias de fontes específicas de pesquisa, estudiosos, cada vez mais, combinam elementos de cada uma (Klinj, 2014; Lotta, 2018; Marques, 2019; Canato \& Bichir, 2021). Se, por um lado, as abordagens relacionais quantitativas são vistas com desconfiança, por ignorarem o caráter mutável das redes sociais, por outro, elas proporcionam informações sobre a estrutura como um todo, complementando o estudo das relações entre atores. Neste trabalho, considerou-se oportuno conjugar técnicas quantitativas e qualitativas no intuito de lidar com a complexidade do fenômeno investigado. Para apresentar as estruturas relacionais, utilizou-se a quantificação na identificação e tratamento dos dados relacionais a partir da perspectiva da análise de rede social (ARS), que utiliza sociogramas e indicadores para representar os padrões de relações entre atores.

Aliados ao emprego de métodos mistos, destaca-se a aplicação dos conceitos de capital social e de laços fracos e fortes, os quais ampliam o olhar sobre a influência das redes na execução do PMCMV-E. O capital social é um recurso socioestrutural de determinado grupo, que facilita as ações dos membros nessa estrutura e que permite coordenar ações com maior eficiência e benefício mútuo para os integrantes dessa rede social (Coleman, 1991). Diferente de outros capitais, seu volume cresce com o uso e possui potencial para aumentar a ação coletiva e fortalecer a colaboração. O capital social é uma força poderosa para a promoção de projetos e explica a capacidade de determinados grupos produzirem ações coletivas de forma eficaz.

O conceito de laços fracos e fortes, por sua vez, foi desenvolvido por Granovetter (1973), que investiga como se situam os atores em uma determinada estrutura social e quais os efeitos dessas posições. Os laços fracos - relações caracterizadas pela menor proximidade entre os atores - podem estabelecer pontes entre variados grupos sociais, permitindo que um indivíduo saia do seu meio social e acesse informações e contatos de outros meios (Granovetter, 1973, Burt, 1992). Estudos empíricos como de Maneschy e Klavdahl (2007) e de Freitas, Ferreira e Freitas (2019), apontam que a presença de capital social em uma estrutura indica a existência de laços fortes, mas também, a de laços fracos, os quais permitem a ampliação da rede de relações no contexto de produção de políticas públicas. Importa-se salientar que o entendimento dessas interações passa, necessariamente, pela análise dos contextos histórico, político, social e institucional, nos quais as variadas dinâmicas encontram-se imersas (Tilly \& Goodin, 2006; Granovetter, 2007).

\section{Procedimentos Metodológicos}

Esta pesquisa foi caracterizada como descritiva, de abordagem interpretativa e com natureza mista. A dimensão empírica se ateve ao caso analisado em Conselheiro Lafaiete-MG, município que abriga o maior conjunto habitacional entregue pela modalidade Entidades em MG: o Residencial Dom Luciano, com 142 moradias. O caso em análise é de tipo instrumental (Stake, 2000). Foi escolhido tanto pela singularidade do Residencial em Conselheiro Lafaiete e na própria jurisdição da GIHAB-BH - responsável por aprovar os projetos do PMCMV -, quanto pela rica trajetória de reivindicação da Associação dos Sem-Teto de Conselheiro Lafaiete (ASTCOL), a Entidade Organizadora (EO), iniciada, organizadamente, há 27 anos no município.

A pesquisa foi operacionalizada em duas etapas: (i) análise dos normativos sobre o PMCMV-E; e (ii) trabalho de campo. Em conjunto, as etapas buscaram descrever as redes de atores formadas, identificar o conteúdo das inter-relações desenvolvidas durante o processo e analisar como essa dinâmica interferiu na execução do Programa.

Na primeira etapa, para estudar o corpo legislativo do Programa, fez-se uso da análise documental nas principais portarias, resoluções e Instruções Normativas (IN) que o regulamentam (Figura 2). A intenção foi identificar os elementos formais que caracterizam sua implementação. 
Figura 2: Quadro Normativo do PMCMV-E analisado

\begin{tabular}{|l|l|}
\hline Documento & Descrição \\
\hline $\begin{array}{l}\text { Resolução 141, } \\
10 / 06 / 2009\end{array}$ & $\begin{array}{l}\text { Dispõe sobre o emprego de recursos do Fundo de } \\
\text { Desenvolvimento Social, criando o PMCMV-E em seus aspectos } \\
\text { gerais }\end{array}$ \\
\hline $\begin{array}{l}\text { Resolução 182, } \\
18 / 08 / 2011\end{array}$ & $\begin{array}{l}\text { Regulamenta a Fase II do PMCMV-E. Alteram-se os limites de } \\
\text { renda bruta mensal dos beneficiários e do financiamento por } \\
\text { unidade habitacional. }\end{array}$ \\
\hline $\begin{array}{l}\text { Portaria 107 de } \\
26 / 02 / 2012\end{array}$ & $\begin{array}{l}\text { Dispõe sobre diretrizes gerais, critérios para habilitação, } \\
\text { cronograma, regularidade institucional e qualificação. }\end{array}$ \\
\hline $\begin{array}{l}\text { Manual do } \\
\text { Beneficiário }\end{array}$ & $\begin{array}{l}\text { Apresenta informaçôes gerais sobre o PMCMV-E, desde } \\
\text { orientação aos beneficiários, aos gestores publicos e à } \\
\text { sociedade em geral. Elenca orientações técnicas e projetuais. }\end{array}$ \\
\hline $\begin{array}{l}\text { Termo de Adesão ao } \\
\text { PMCMV }\end{array}$ & $\begin{array}{l}\text { Termo que firma a parceria entre a União e o Município que } \\
\text { participa do Programa. Traz as principais atribuiçôes e } \\
\text { compromissos que ambas as partes se comprometem ao } \\
\text { firmar o acordo. }\end{array}$ \\
\hline
\end{tabular}

Fonte: Elaboração própria.

De posse das informações normativas, procedeu-se à pesquisa de campo (etapa 2) para analisar os aspectos contingenciais e contextuais da implementação do Programa. O trabalho de campo foi realizado entre agosto e novembro de 2017 e foram quatro visitas ao município, contabilizando 15 dias na cidade.

Em paralelo à análise documental, que permitiu a identificação inicial dos atores e de seus papéis, foram conduzidas entrevistas com esses agentes na busca de se obter informações sobre como ocorreram as respectivas atuações e dos diferentes acordos e conflitos presentes nesse processo. As entrevistas ocorreram a partir de roteiros semiestruturados, os quais foram elaborados considerando as atribuições de cada grupo: (i) entidade; (ii) poder público local; (iii) CEF; e (iv) empreiteira.

Por parte da associação, foram entrevistados seus dirigentes fundadores (2); membros das Comissões de Acompanhamento da Obra e de Representantes (2); beneficiários (5); assistente social (1); e representante da União Nacional por Moradia Popular (UNMP) (1) - movimento ao qual a EO é filiada. Oriundos da $\mathrm{CEF}$, foram entrevistados coordenadores da GIHAB (2); técnicos (2); e gerentes em nível local e nacional do Programa (2). Do poder público local, foram entrevistados dois secretários; e, da empreiteira, ouviu-se o encarregado da obra (1). Foram realizadas 20 entrevistas, totalizando mais de 18 horas de relatos gravados, os quais foram posteriormente transcritos e analisados.

As informações coletadas via análise documental permitiram identificar as fronteiras formais da rede de atores, enquanto as coletadas por entrevistas, registraram o conteúdo das interações, bem como novos atores que surgiram nesse processo. Para tanto, de modo geral, as entrevistas levaram em consideração a identificação e a trajetória dos atores (história), com quem determinada organização e seus participantes interagem direta e indiretamente (conectividade), os padrões de interação (densidade) e a natureza predominante da relação - conflito, cooperação, relacionamento autocentrado - (centralidade dos atores). Esses dados ajudaram, posteriormente, a construir a gênese das relações e a elaborar representações gráficas das redes (Figura 4).

Para tratamento das informações coletadas foram empregadas as técnicas Análise de Conteúdo e Análise de Redes Sociais. A operacionalização da Análise de Conteúdo foi dividida em três etapas, conforme indicação de Bardin (2009). A partir do quadro teórico definido para este trabalho, identificaram-se três categorias analíticas, de grade fechada (Bardin, 2009), as quais estão dispostas na Figura 3. 
Figura 3: Categorias analíticas

\begin{tabular}{|l|l|}
\hline Categoria & Definição \\
\hline Grupo de atores & $\begin{array}{l}\text { Especificação dos atores participantes e de seus } \\
\text { respectivos papéis e ações no processo de implementação. }\end{array}$ \\
\hline $\begin{array}{l}\text { Relações entre os } \\
\text { implementadores }\end{array}$ & $\begin{array}{l}\text { Análise da natureza e do conteúdo sociopolítico das } \\
\text { relações, e caracterização das propriedades relacionais } \\
\text { observadas. }\end{array}$ \\
\hline Fatores contextuais & $\begin{array}{l}\text { Análise dos contextos histórico (trajetória dos atores), } \\
\text { institucional, econômico e político aos quais o processo de } \\
\text { implementação e as relações sociais estão imersos. }\end{array}$ \\
\hline
\end{tabular}

Fonte: Elaboração própria.

Com as informações tratadas pela Análise de Conteúdo, à medida que os principais atores ${ }^{[i i]}$ desse processo foram identificados, suas atribuições conhecidas e os conteúdos de suas relações analisados, buscouse investigar em que lugar esses agentes se situam na estrutura social. Esse olhar posicional tem sido objeto da morfologia das redes e auxilia na compreensão das configurações relacionais formadas no decorrer do processo de implementação do PMCMV-E em Conselheiro Lafaiete.

Para representar essa arquitetura das dinâmicas relacionais foi empregada a perspectiva da Análise de Redes Sociais, a qual disponibiliza indicadores que permitem apresentar a configuração reticular entre os atores (Scott, 2009; Lazega \& Higgins, 2014). Na Figura 4, apresentam-se as medidas de rede utilizadas nesta pesquisa.

Figura 4: Medidas de rede utilizadas

\begin{tabular}{|c|c|}
\hline Medidas & Descrição e importância \\
\hline Tamanho & $\begin{array}{l}\text { Refere-se ao número de atores que integram uma rede. Além } \\
\text { dos agentes já previstos na legislação, o processo de } \\
\text { implementação é caracterizado pela influência de outros } \\
\text { atores que surgem a partir das especificidades de cada } \\
\text { contexto. }\end{array}$ \\
\hline Conectividade & $\begin{array}{l}\text { Uma rede é considerada conectada se existe um caminho } \\
\text { entre qualquer par de nós que possibilita que recursos sejam } \\
\text { mobilizados. Por outro lado, uma rede fragmentada é } \\
\text { formada por vários subgrupos não conectados entre si. A } \\
\text { conectividade é necessária para alavancar recursos e } \\
\text { informações em um processo que se desenha interativo e com } \\
\text { responsabilidades compartilhadas. }\end{array}$ \\
\hline Densidade & $\begin{array}{l}\text { Descreve o nivel geral de conexão entre os membros de uma } \\
\text { rede. É calculada a partir da proporção de relações existentes } \\
\text { em relação às potencialmente presentes, se cada ator } \\
\text { possuisse relações com todos os outros. A alta densidade } \\
\text { permite fluxo mais livre de recursos, favorecendo processos } \\
\text { de aprendizagem e a sinergia entre grupos. Uma baixa } \\
\text { densidade pode representar fracas relaçôes de socialização, } \\
\text { reduzindo processos colaborativos. }\end{array}$ \\
\hline Centralidade & $\begin{array}{l}\text { Diz respeito à localização do ator na rede em relação aos } \\
\text { demais identificados. Neste trabalho empregou-se a } \\
\text { Centralidade de Grau, que consiste em calcular o número de } \\
\text { arcos incidentes no ator ou o número de nodos com os quais } \\
\text { possui adjacência. Atores centrais podem agir, } \\
\text { colaborativamente, de duas maneiras: como pontes, trazendo } \\
\text { informações, conhecimentos, percepçóes e inovaçôes; e como } \\
\text { núcleos de comunicação, disseminando esses recursos } \\
\text { disponiveis. }\end{array}$ \\
\hline
\end{tabular}


O tratamento dos dados relacionais foi realizado a partir dos softwares UCINET e NetDraw, os quais permitem identificar e representar os atributos estruturais das relações analisadas. Com base nas informações relacionais, os referidos softwares possibilitam a visualização de uma série de indicadores e a construção dos respectivos sociogramas, apresentando as características de suas interações, as posições dos atores e os elos que os unem.

\section{Resultados e Discussões}

\subsection{O processo formal de implementação do PMCMV-E}

A execução de uma política pública é regulamentada por dispositivos jurídico-legais. Em consequência disso, apresenta-se, inicialmente, o processo de implementação do PMCMV-E a partir do seu quadro normativo. A organização desse processo de forma linear, sequenciando as etapas da implementação, permitiu abrir a "caixa preta" da operacionalização formal do Programa, de forma a preencher as lacunas necessárias à sua compreensão in loco.

Resumidamente, o processo de implementação do PMCMV-E começa com a mobilização de certo grupo de famílias, juntamente com o interesse de determinada associação em produzir habitações para seus afiliados. Contudo, além de estar juridicamente constituída, para estar apta a formalizar projetos à CEF - os quais serão avaliados do ponto de vista técnico e financeiro pelas GIHAB's -, a associação deve participar de um processo de habilitação sob responsabilidade do MCidades, visando avaliar se ela possui a capacidade de executar e/ ou intermediar a construção de habitações.

Paralelamente à tentativa de habilitação, essa associação inicia a busca por uma área com potencial para a construção do empreendimento. Esse terreno deve ter a documentação regularizada e passar por estudos de viabilidade técnica e econômica, realizados pela assessoria técnica, para que se possa, finalmente, formalizar a proposta de contratação do empreendimento. Com estudos e documentações verificados e validados pela GIHAB, a obra está finalmente apta a ser contratada, dependendo de sua confirmação a ser feita pelo MCidades. Todo esse processo inicial é descrito como a etapa de pré-obra do empreendimento e, quando comparada a outras fases da implementação, observa-se a concentração de atividades a serem realizadas nesse período, levando autores a utilizar a expressão "novela da contratação" para descrevê-lo (Lago, 2012; Jesus, 2016).

Uma vez selecionada a proposta, inicia-se o processo de construção do residencial, a partir do qual um novo conjunto de disputas estará relacionado às características da modalidade de operação, do regime de construção, da assessoria técnica, do perfil da entidade e de seus beneficiários e das interações com outros atores. Posteriormente, ao término da obra, dá-se início a etapa de legalização do empreendimento, em que é necessário a obtenção de uma série de documentos e registros.

$\mathrm{Na}$ Figura 5, ilustra-se o desenho de implementação do programa. 


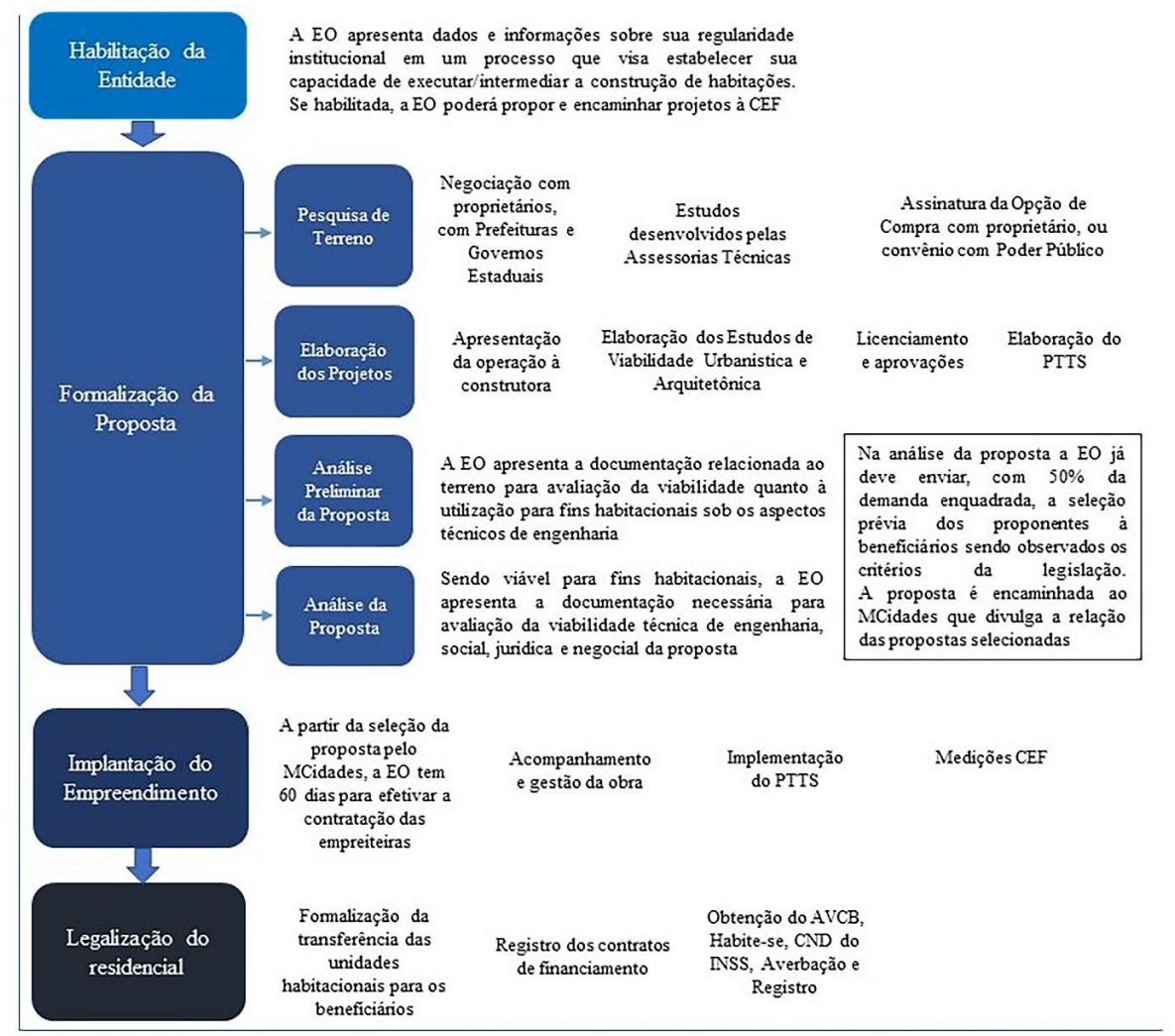

Figura 5: Esquema do processo de implementação do PMCMV-E

Fonte: Elaboração própria com base em Brasil (2013). Nota: Siglas: Plano de Trabalho Técnico Social (PTTS); Certidão Negativa de Débito do Instituto Nacional do Seguro Social (CND do INSS).

O esquema descrito é o que orienta formalmente a implementação do PMCMV-E. No entanto, de um ponto de vista empírico, cada ambiente será responsável por materializar de forma particular a execução dessa política habitacional. No caso analisado, observou-se, in loco, dois períodos com dinâmicas relacionais distintas devido a conflitos que surgiram após a contratação do residencial, alterando, dessa forma, a rede de implementação. Tendo em vista a fluidez das relações, optou-se por apresentar o processo investigado a partir de um recorte temporal desses dois momentos: (i) O processo de contratação do empreendimento, e (ii) A execução do Residencial Dom Luciano.

\subsection{O Processo de Contratação do Empreendimento}

Dentre os diversos elementos analisados na fase de contratação, dois foram, reiteradamente, ressaltados como fundamentais para explicar a unicidade do Residencial Dom Luciano: a alta coesão interna da associação e a realização de uma parceria entre atores locais para superar os desafios relacionados à contratação do empreendimento.

Traduzida pela confiança entre os membros e sua cooperação, a alta coesão interna ou o alto capital social observado na associação dos sem-teto, é fruto de 23 anos de luta pela moradia digna até a inauguração do empreendimento. Esse período é marcado por conquistas - como obtenção de terreno e sede própria para associação -, e de tentativas frustradas de se implementarem outros programas habitacionais - a entidade tentou executar outros quatro programas até conseguir implementar o PMCMV-E, após 11 anos:

Nas primeiras visitas, a gente percebia que a luta era velha. Eles estavam incrustados naquela mobilização. É muito mais fácil você lidar com pessoas que sabem pelo que estão lutando. Outra coisa é você montar uma instituição artificial. Ali não, a luta 
pela moradia ali era uma coisa velha (...). Eu achava as assembleias maravilhosas, uma presença maciça dos associados, aquilo me marcou muito. Isso para nós é um ponto fortíssimo, o sucesso de qualquer ação coletiva depende disso. (Técnico CEF 01).

Por trás do engajamento social estavam as reuniões realizadas durante anos, as diversas ações e mutirões concretizados conjuntamente e o compartilhamento de um ideal coletivo que fortaleceram os vínculos entre os membros da associação e sua confiança recíproca (Coleman, 1991). A compreensão sobre o capital social só pode ser realizada a partir da contextualização temporal e espacial do fenômeno investigado, e é justamente a compreensão da historicidade desse processo que explica o porquê de o movimento ter se mostrado, de forma geral, engajado e resiliente.

Por conta desse histórico de luta pela moradia, a EO não encontrou dificuldades no primeiro desafio que o programa apresenta: o processo de habilitação da entidade. Em duas décadas de existência, a associação acumulou certificados que comprovaram a participação de seus membros em conferências, congressos, seminários e atividades formativas relacionadas à luta pela moradia. Isso, aliado à sua regularidade institucional e ao seu tempo de existência, possibilitou à associação receber uma alta nota no processo de habilitação.

Uma vez apta a propor e encaminhar projetos à CEF, a associação firmou uma parceria com o Sindicato de Engenheiros no Estado de Minas Gerais (Senge) para auxiliar na elaboração de um projeto a ser enviado para a então Gerência de Apoio ao Desenvolvimento Urbano (GIDUR) da CEF, responsável, à época, pela análise técnica e financeira para contratação na modalidade. Habilitada e com um parceiro encarregado pela responsabilidade técnica do empreendimento, a associação buscou, por quase dois anos (entre meados de 2011 e 2012), viabilizar o projeto pelo regime de Autogestão - em que a EO contrata profissionais ou empresas para execução parcial dos serviços necessários. Contudo, uma série de conflitos com o agente operador do programa marcou esse período de tratativas. Por não acreditar na capacidade da associação em executar um empreendimento pelo regime de Autogestão, a GIDUR exigiu que se optasse pelo regime de empreitada global - regime no qual uma empreiteira assume a construção do empreendimento. Sem alternativa, a associação, a partir de 2012, iniciou a busca por um parceiro para executar o empreendimento sob regime de empreitada global. Essa busca duraria mais dois anos até encontrar uma empresa parceira.

Paralelamente à procura por uma construtora, existiam exigências burocráticas locais a serem cumpridas para a contratação do residencial. Os normativos da modalidade estabelecem uma série de obrigações sobre a necessidade de outros atores se responsabilizarem pela construção da infraestrutura no terreno do empreendimento. E, portanto, a entidade dependeria da colaboração do poder público local para viabilizar a contratação do empreendimento. Nesse sentido, a nomeação de dois secretários pela nova gestão municipal - no caso, o secretário de desenvolvimento social e o de planejamento -, que mobilizaram recursos e vínculos proativamente, foi fundamental para o início de uma profícua parceria que conseguiu, posteriormente, superar as barreiras para a contratação do empreendimento. Além da parceria iniciada em 2013 entre a prefeitura e a associação, em janeiro de 2014, a chegada de um novo gerente regional para a agência da CEF em Conselheiro Lafaiete também foi um marco significativo para o caso em análise.

Deve-se salientar que o alto capital social da associação se mostrou, sozinho, incapaz de contornar as barreiras de quatro programas federais aos quais se tentou acessar anteriormente, e se mostrava insuficiente para viabilizar a contratação do empreendimento no PMCMV-E. Foi imprescindível que burocratas da prefeitura e da agência da CEF, se empenhassem individualmente para a contratação do residencial. Nesse sentido, pontua-se o trabalho de Viana (2019), que evidencia empenho similar na atuação de burocratas do MCidades para diminuição de resistências locais à implementação do PMCMV-E. Foi necessário a atuação de servidores federais para proporcionar maior inclusão de "sem-teto" nas decisões sobre os projetos habitacionais (Viana, 2019), tal como preconizado pelos formuladores da política pública. Esses fatos exemplificam, empiricamente, o poder do componente social-relacional, considerando que pode se desenvolver em contextos adversos e possui força para contornar os desafios que obstruem a execução de políticas públicas (Maneschy \& Klavdahl, 2007; Abers, 2015; Freitas et al., 2019). 
Três anos após o início das tratativas relacionadas ao PMCMV-E, a ASTCOL, com apoio de diferentes atores públicos e não públicos, havia conseguido atender diversas exigências para efetivar a contratação. Restava, por fim, a aprovação da viabilidade técnica do empreendimento a cargo da GIDUR-BH, mas os antigos conflitos continuavam. Contudo, em abril de 2014, a CEF extinguiu a GIDUR e criou a GIHAB - nova responsável pela análise técnica de todos os projetos relacionados à modalidade. Essa mudança institucional promoveu alterações importantes no quadro de funcionários do órgão, as quais afetaram o conteúdo das interações da rede. Em agosto de 2014, o projeto da EO foi, finalmente, contratado. Embora existam diferentes narrativas sobre o grau de influência da nova gerência para a conclusão desse processo, as entrevistas são convergentes quanto ao modo como a equipe da GIHAB se mostrou empenhada em colaborar para superar os desafios ainda existentes.

Como meio de representar a configuração relacional formada no decorrer do processo de contratação do empreendimento, a Figura 6 apresenta os atores envolvidos nesse processo, o vetor de suas interações e a força das relações mantidas pela associação. Em virtude de a maior parte dessa etapa ter acontecido com a participação da GIDUR-BH, optou-se por representar as interações desse período com a presença desse órgão. Na configuração relacionada à construção do residencial, a participação da GIHAB está presente.

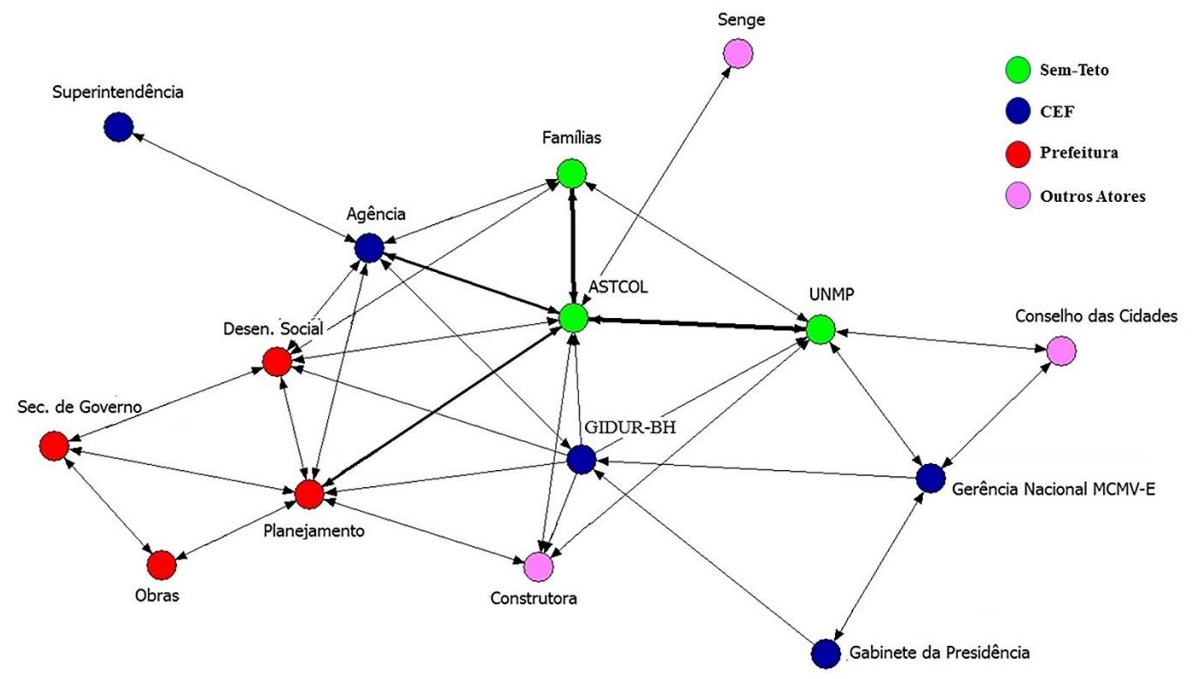

Figura 6: Estrutura das interações relacionadas à contratação do empreendimento Importar imagen Fonte: Resultados da pesquisa.

A partir da Figura 6, observa-se, graficamente, a centralidade dos agentes que influenciaram o processo analisado. Esse olhar posicional é mais um elemento que dá subsídios para discutir sobre como diferentes redes são formadas a partir das especificidades de cada processo. Destaca-se a centralidade que atores da prefeitura (Planejamento e de Desenvolvimento Social), da CEF (agência local e GIDUR) e do Movimento dos Sem-Teto (ASTCOL e UNMP) tiveram na rede formada para a contratação do empreendimento. Notase, contudo, duas diferentes tendências em relação a essa centralidade.

Por um lado, observa-se, a partir da reciprocidade das relações, a representação da parceria firmada entre poder público local, agência da CEF e movimento dos sem-teto. Essa parceria está representada nos laços fortes e em seu consequente capital social, estabelecidos entre associação e secretaria de planejamento, e associação e agência da CEF. Ao se tornarem elos entre grupos, esses agentes se caracterizaram por exercerem funções de ponte e de núcleos de comunicação. Foram os intermediadores (brokerage) que estabeleceram a conexão entre diferentes redes (Burt, 1992). Ressalta-se a capacidade de os sem-teto acionarem laços fracos para a ampliação da rede com outros importantes atores institucionais (Granovetter, 1973), pois alguns, posteriormente, transformaram-se em laços fortes. 
Por outro lado, destaca-se o relacionamento autocentrado da GIDUR, representado por suas conexões unidirecionais na estrutura. Esse ator é caracterizado pelo baixo número de indicações indegree, que são as trocas recebidas, e pelo alto envio de fluxos, indicações outdegree, o que lhe confere uma alta capacidade de alcançar outros atores e, ao mesmo tempo, ter poucos atores que o influenciam, representando maior autonomia. Essa dicotomia se justifica pelo comportamento autocentrado desse ator durante a contratação do empreendimento, exercendo sua autoridade formal de forma unilateral sobre os outros atores. Essa situação foi alterada em 2014, após a transformação da GIDUR em GIHAB, quando novos burocratas assumiram cargos de coordenação e técnico.

Salienta-se, ainda, a presença de agentes federais não especificados nos normativos e que fizeram parte da rede influenciando o processo de contratação. Por ser membro do Conselho Nacional das Cidades, o representante da UNMP estabeleceu uma série de laços fracos, em um contexto político específico, possibilitando que as dificuldades locais da associação fossem apreciadas em nível federal. A convergência entre as próprias características do PMCMV-E, em um contexto favorável de um partido centro-esquerda no poder, permitiu que os movimentos de luta pela moradia transitassem por redes tradicionalmente distantes, como igualmente demonstra o trabalho de Tatagiba e Teixeira (2016). Ao combinar variáveis explicativas como a força dos movimentos dos sem-teto e as características do contexto -, as autoras evidenciaram como a atuação dos atores foi condicional e contingente à presença de fatores externos à época (Tatagiba \& Teixeira, 2016). Nos termos de Sabatier e Weible (2007), a conjuntura descrita se refere a uma janela de oportunidade política, que amplia a possibilidade de se mobilizar recursos e vínculos a fim de superar entraves na produção de políticas públicas.

Essa relevante relação entre a dimensão política das diretrizes públicas e suas características contingenciais, é ressaltada em importantes estudos na literatura (Pollitt, 2013 Abers, 2015; Pires et al., 2018). Segundo Tilly e Goodin (2006), os processos políticos estão sujeitos ao ambiente em que ocorrem, assim, a compreensão dos contextos histórico, institucional, econômico e político auxiliam a explicar como certos grupos chegaram a determinadas escolhas e produziram, posteriormente, determinados resultados. Uma correta compreensão do fenômeno social passa, necessariamente, pela localização do contexto social no qual o fenômeno ocorre, devendo ser, portanto, espacial e temporalmente contextualizados (Tilly \& Goodin, 2006; Granovetter, 2007).

Quanto às medidas de rede, na Tabela 1 são apresentados indicadores sobre a rede formada no processo de contratação do Residencial Dom Luciano. São analisados os resultados quanto à caracterização em nível global da rede (total de agentes, de conexões e densidade).

Tabela 1: Resultados da caracterização geral da rede de contratação do empreendimento

\begin{tabular}{lll}
\hline Medidas & Resultado & Desvio Padrão \\
\hline N. ${ }^{\circ}$ de atores & 15 & - \\
\hline Relações & 31 & - \\
\hline Densidade das relações & $27,1 \%$ & 0.445 \\
\hline Média de indicações (InDegree) & 3,8 & 2,23 \\
\hline Média de indicações (OutDegree) & 3,8 & 1,90 \\
\hline
\end{tabular}

Fonte: Resultados da pesquisa.

Sobre o número de agentes que integram a rede analisada, no processo de contratação do Residencial Dom Luciano foram identificados 15 atores coletivos que influenciaram diretamente esse fenômeno. A rede foi estabelecida a partir do reconhecimento dos próprios entrevistados dos agentes, que tiveram papeis importantes no transcorrer dessa história.

Foram contabilizadas 31 conexões, sendo que, nesse período, 25 foram relações recíprocas e seis não recíprocas. Isso equivale a dizer que cerca de $81 \%$ das relações estabelecidas entre os diferentes atores, a partir, 
principalmente, de 2013, foram, predominantemente, colaborativas. As relações colaborativas permitiram que se mobilizassem recursos e informações por toda a rede, conectando os variados grupos por ligações diretas ou por meio de outros atores intermediários. A centralidade da associação foi observada pelo maior número de fluxos recebidos e destinados, caracterizando-a como o agente com maior capacidade de alcançar os outros e ser mais acessado por outros. A entidade foi, assim, um núcleo de comunicação da rede que capilarizou os recursos entre os variados grupos.

O predomínio de relações colaborativas, $81 \%$ bidirecionais, aliada à densidade observada, $27,1 \%$, ilustram a exitosa estrutura que conseguiu contornar as diversas barreiras que caracterizaram a "novela da contratação". A parceria local entre as secretarias municipais de Conselheiro Lafaiete, a agência da CEF no município e a associação, obteve êxito quanto ao cumprimento das variadas obrigatoriedades legais exigidas pelos normativos do programa.

\subsection{A Execução do Residencial Dom Luciano}

Se o processo de contratação do empreendimento perdurou por cerca de 42 meses ( 3 anos e meio), a execução do programa em si, isto é, a construção e regularização do residencial, durou 18 meses. Isso porque a ASTCOL já possuía terreno próprio anteriormente doado pela prefeitura, situação incomum para associações que contratam o programa, o que demonstra a sua singular trajetória. Caso a entidade não tivesse essa área, certamente esse processo seria ainda mais complexo, uma vez que a compra do terreno é constantemente debatida na literatura como um dos grandes entraves do programa (Lago, 2012; Jesus, 2016).

Cerca de 1 ano e 6 meses depois do início das obras, as 142 casas do empreendimento habitacional foram finalizadas e o Residencial Dom Luciano foi inaugurado em julho de 2016. Embora a duração de cada processo tenha sido diferente (contratação e execução), ambos foram marcados por conflitos e acordos que alteraram a natureza e a consequente configuração das interações sociais. A Figura 7 apresenta os atores envolvidos no processo de construção do Residencial Dom Luciano, o vetor de suas interações e a força das relações mantidas pela associação.

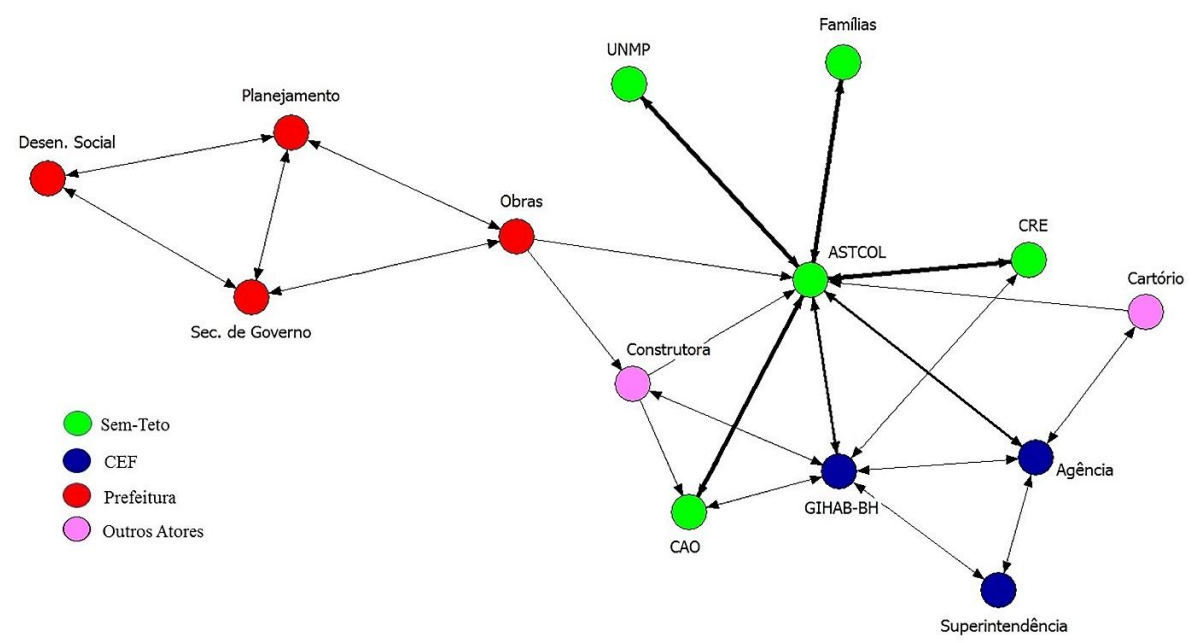

Figura 7: Estrutura das interações durante a construção do empreendimento. Fonte: Resultados da pesquisa.

A configuração reticular apresentada na Figura 7 é diferente da observada na contratação do empreendimento. Em função das próprias particularidades da fase de construção e regularização do residencial, essas diferenças são inicialmente previstas. Entretanto, destaca-se como os fatores contingenciais foram igualmente responsáveis pela formação da nova configuração, bem como de novos laços fortes (Tilly \& Goodin, 2006; Granovetter, 2007). Dois dos principais grupos de atores com os quais o movimento dos 
sem-teto interagia - CEF e poder público local - apresentaram naturezas relacionais distintas das observadas no processo de contratação, a partir de novos conflitos e acordos ocorridos nesse processo.

De um lado, o poder público local, que havia sido um dos pilares na primeira rede, foi o centro do maior conflito durante a construção do residencial, alterando de forma importante a configuração da rede. $\mathrm{Na}$ fase de contratação do residencial, para que a GIHAB aprovasse o projeto, a prefeitura assumiu responsabilidades como a terraplanagem do terreno e a implantação da infraestrutura hidráulica no empreendimento. Contudo, na hora de executar essas ações, a secretaria de obras argumentou que, devido a sua pequena estrutura, ela não poderia "abrir mão" de máquinas alocadas em outras obras públicas. Esse conflito foi responsável por desfazer o núcleo de colaboração formado para contornar as barreiras da contratação.

De outro lado, a partir da transformação de GIDUR para GIHAB, esse ator se tornou um núcleo de comunicação nesse segundo momento. Ele exerceu importantes funções de mediação nos embates entre empreiteira e associação e foi o grande orientador da associação - ilustrada pela nova força do laço. Essas reconfigurações observadas na rede de relações circunscritas ao processo de implementação do PMCMV-E, ilustram o caráter fluído de uma estrutura reticular, em que seu formato é produto das especificidades do novo processo, bem como das novas disputas e acordos desse ambiente.

$\mathrm{Na}$ Tabela 2 são apresentadas as medidas de rede da configuração formada para a execução do Residencial Dom Luciano. São analisados os resultados quanto à caracterização da rede em seu nível global (total de agentes, de conexões e densidade).

Tabela 2: Resultados da caracterização geral da rede de construção do empreendimento

\begin{tabular}{lll}
\hline Medidas & Resultado & Desvio Padrão \\
\hline N. ${ }^{\circ}$ de atores & 14 & - \\
\hline Relações & 23 & - \\
\hline Densidade das relações & $22 \%$ & 0.42 \\
\hline Média de indicações (InDegree) & 2,5 & 2,1 \\
\hline Média de indicações (OutDegree) & 2,5 & 1,53 \\
\hline
\end{tabular}

Fonte: Resultados da pesquisa.

Sobre o número de atores que influenciaram diretamente o processo de construção e legalização do empreendimento, foram identificados 14 atores coletivos. Embora tenha sido um processo com duração notadamente menor do que a contratação do residencial, identificou-se apenas um ator a menos nessa segunda configuração.

Foram registradas 23 relações, das quais 18 recíprocas e cinco não recíprocas. Ou seja, $78 \%$ das relações nesse período foram predominantemente colaborativas. Apesar de o percentual de interações recíprocas ser similar ao do processo de contratação, o que se observa é um número de conexões $30 \%$ menor do que na primeira configuração. A diminuição das relações é explicada, principalmente, pela afastada participação do poder público local nesse processo. Os secretários que haviam sido núcleos e pontes, agora foram nós com discretas atuações.

A medida de densidade também apresentou um percentual inferior à estrutura anterior. Foram registrados $22 \%$ do total de laços possíveis entre os membros do processo de construção do residencial, ante $27 \%$ na contratação. Destaca-se, assim, que apesar das alterações de natureza nas relações da GIHAB-BH, em que esse ator se tornou figura-chave no novo processo, essa segunda configuração apresentou uma estrutura menos coesa do que a inicial.

Ressalta-se, ainda, a posição assumida pela Secretaria de Obras nessa segunda etapa. Esse ator apresentou quatro conexões, sendo duas unidirecionais. $\mathrm{O}$ motivo foi esse ator ter alegado que não poderia executar as obrigações assumidas na contratação do Residencial. A falta/ineficiência de instrumentos legais que obrigassem a Secretaria a cumprir, de imediato, suas responsabilidades, fez com que empreiteira e associação 
ficassem em uma posição de dependência nessa relação, sujeitos à disposição da secretaria em cumprir a sua parte. Por esse motivo, a Secretaria de Obras se caracteriza como um ator central, com alta capacidade de alcançar outros atores e, ao mesmo tempo, com maior autonomia entre os atores centrais.

Ao ilustrar por meio da ARS assimetrias de relações, diferenças de configuração entre as redes e alterações na posição de dependência entre os atores, este trabalho confirma o caráter dinâmico das redes sociais. Apesar dessas estruturas reticulares não serem estáticas, são muitas vezes tratadas como "fotografias", por estudos que desconsideram a influência da politics sobre o formato da ação pública, simplificando um processo que é a expressão das interações, disputas e acordos ocorridos em um campo (Tatagiba \& Teixeira, 2016; Viana, 2019), sendo, portanto, intrinsecamente fluido.

\section{Conclusões}

A análise da implementação do PMCMV-E sob a ótica relacional, indicou que os atores e suas interações se revelaram fundamentais para a compreensão do fenômeno. Foram evidenciadas dimensões de conflito e ambiguidade, características teoricamente atribuídas, muitas vezes, apenas às etapas de agenda e formulação do Ciclo de Políticas Públicas. Logo, mais do que um output dessas fases, evidenciou-se o caráter intrinsecamente interativo e político-contextual do processo de implementação de uma política pública.

A análise dos grafos e dos índices relacionais demonstrou as mudanças da rede ao longo do processo de implementação. Observou-se que, apesar de a execução da modalidade ser delineada com base em seu desenho institucional, foi a forma como atores interagiram que condicionou os recursos ofertados e investidos em sua implementação. Isso significa dizer que a execução do programa foi o resultado das disputas e acordos (politics) ao longo dos cinco anos de sua duração (contratação e execução). Além disso, foi revelado o enraizamento na realidade social em que o programa foi executado, sendo o processo de implementação, portanto, moldado pelo ambiente local. $\mathrm{O}$ formato da intervenção foi influenciado pelo legado histórico da associação, pela trajetória individual dos agentes locais e pelos contextos político-institucionais dos diferentes atores públicos.

Ao apresentar diferentes aspectos políticos-contextuais que possibilitam compreender a unicidade do Residencial Dom Luciano, este trabalho confirma a importância de se investigar as dimensões históricas, institucionais, políticas e sociais, dimensões que conformam o ambiente no qual a política pública será implementada. $\mathrm{O}$ entendimento desses elementos possibilita observar a implementação como um processo socialmente construído, permeado de ambiguidade e conflito, devendo ser, para sua compreensão, espacial e temporalmente contextualizado.

Do ponto de vista teórico, esses resultados convergem a visão processual do Policy Process com a perspectiva relacional, duas vertentes ainda pouco utilizadas em conjunto e que se revelaram profícuas. Academicamente, esta pesquisa contribui ao apresentar formas alternativas de emprego da Policy Network, sendo a abordagem relacional mista uma estratégia capaz de desvelar a dimensão política em um fenômeno que é, naturalmente, subjetivo, variável e contextual, como a implementação de políticas públicas. Aos tomadores de decisão e aos beneficiários de políticas públicas, contribui-se ao apresentar a necessidade de considerar elementos subjetivos e relacionais para a efetiva realização dos objetivos para os quais as políticas públicas são dirigidas.

Como continuidade aos estudos, incentiva-se a comunidade acadêmica a explorar, empiricamente, a potencialidade do delineamento adotado em pesquisas que investiguem a formação de redes em fases distintas do processo de políticas públicas, bem como nos diferentes níveis federativos. Por fim, embora a perspectiva relacional possibilite analisar simultaneamente a conjugação entre contexto, atores e interações, ela possui, de forma paralela, limitações quando busca desagregar essas dimensões - o que é igualmente importante para aprimorar o conhecimento científico. Portanto, outros arcabouços conceituais, como o emprego de “mecanismos causais" por exemplo (Tilly \& Goodin, 2006), são recomendados nesse sentido. 


\section{REFERÊNCIAS}

Abers, R. (2015). Ativismo na burocracia? O médio escalão do Programa Bolsa Verde. In P. Cavalcante, G. Lotta. Burocracia de médio escalão: perfil, trajetória e atuação, Brasília: ENAP, 143-176.

Amore, C., Shimbo, L., Rufino, B. (2015) Minha casa... e a cidade? Avaliação do Programa Minha Casa, Minha Via em seis estados brasileiros. Rio de Janeiro: Letra Capital.

Balbim, R., Krause, C., Lima, V. Neto. (2015). Para além do Minha Casa Minha Vida: Uma política de habitação de interesse social? Ipea, No. 2116. Texto para Discussão.

Bardin, L. (2009). Análise de Conteúdo. (5a ed.). Lisboa: Edições 70.

Börzel, T. (1998). Organizing Babylon-On the Different Conceptions of Policy Networks. Public Administration. 76(2), 253-273.

Brasil, 2013. (2013). Programa Minha Casa Minha Vida Entidades-Recursos FDS (Manual). Caixa Econômica Federal. Acesso em abril/2017.

Brasil. (2016). Sistema Eletrônico do Serviço de Informação ao Cidadão, MCidades. Recuperado em 20 setembro, 2016 de http://www.acessoainformacao.gov.br/.

Brasil. (2020) Relatório de Avaliação. Programa Minha Casa Minha Vida. Recuperado em 04 junho, 2021, de https://www.gov.br/cgu/pt-br/assuntos/noticias/2021/04/cgu-divulga-prestacao-de-contas-do-presidenteda-republica-de-2020/relatorio-de-avaliacao-pmcmv.pdf

Brasil. (2021) Pedido de acesso à informação ao Ministério do Desenvolvimento Regional - MDR. Protocolo 59016.000743/2021-96. Fala.BR - Plataforma Integrada de Ouvidoria e Acesso à Informação. Controladoria Geral da União.

Burt, R. (1992). Structural holes: the social structure of competition. Cambridge: Harvard University Press.

Canato, P., Bichir, R. (2021). Intersetorialidade e redes sociais: a implementação de projetos para população em situação de rua em São Paulo. Revista de Administração Pública. Recuperado de http://bibliotecadigital.fgv.br/ ojs/index.php/rap/article/view/83829

Cardoso, A. L. (2013). O programa Minha Casa, Minha Vida e seus efeitos territoriais. Rio de Janeiro: Letra Capital.

Clivaz, C. (2001). Influence des réseaux d'action publique sur le change-ment politique: l'exemple de l'écologisation des politiques suisses etvalaisannes du tourisme, des transports et de l'agriculture. Swiss Political Science Review, 7(1), 19-50.

Coleman, J. S. (1990). Foundations of Social Theory. Cambridge: Harvard University Press.

Dowding, K. (1995). Model of metaphor? A critical review of the policy network approach. Political Studies, 43(1), 136-158.

Freitas, A., Ferreira, M., Freitas, A. (2019). A Trajetória das Organizações de Agricultores Familiares e a Implementação de Políticas Públicas: um estudo de dois casos. Revista de Economia e Sociologia Rural, 57(1), 09-28.

Granovetter, M. (1973). The strength of weak ties. American Journal of Sociology, 78(6), 1360-1380.

Granovetter, M. (2007). Ação econômica e estrutura social: o problema da imersão. RAE-eletrônica, 6(1), 1-41.

Heclo, H. (1978). "Issue networks and the executive establishment". In A. King (Org.). The new American political system. Washington, DC: American Enterprise Institute for Public Policy Research.

Hill, M., Hupe, P. (2014). Implementing Public Policy: An Introduction to the Study of Operational Governance. 3rd ed. London: Sage.

Hupe, P., Hill, M. (2016). And the rest is implementation. Comparing approaches to what happens in policy processes beyond Great Expectations. Public Policy and Administration, 31(2), 103-121.

Jesus, P. M. (2016). The inclusion and access of social housing movements to Minha Casa Minha Vida: the emergence of the Entidades modality. Revista Brasileira de Estudos Urbanos e Regionais, 18(1), 92-110.

Klijn, E. (1998). Policy Networks: An Overview. In: W. Kichert, J. Koppenjan, (Orgs.), Managing Complex Networks. Sage, London, 14-34. 
Klijn, E. (2014). Redes de política e implementação: gerenciando interações complexas. In S Cropper, et al. (Orgs.), Handbook de relações interoganizacionais da Oxford, Porto Alegre: Bookman, 108-133.

Lago, L. (2012) Autogestão habitacional no Brasil: utopias e contradições. Rio de Janeiro: Letra Capital: Observatório das Metrópoles.

Lavalle, A., Rodrigues, M., Guicheney, H. (2019) Agência local e indução federal: A operação da política municipal de habitação em Recife e Curitiba. Revista de Sociologia e Politica, 27(71),1-27.

Lazega, E., Higgins, S. (2014). Redes sociais e estruturas relacionais. 1a ed. Belo Horizonte: Fino Traço.

Leifeld, P. (2007). Policy Networks: A Citation Analysis of the Quantitative Literature. University of Konstanz, Konstanz.

Lindblom, C. (1981). O Processo de Decisão Política. Ed. Universidade de Brasília, Brasília.

Lotta, G. (2018). Burocracia, redes sociais e interação: uma análise da implementação de políticas públicas. Revista de Sociologia e Política, 26(66), 145-173.

Lotta, G. (2019). A política pública como ela é: contribuições dos estudos sobre implementação para a análise de políticas públicas. In G. Lotta (Org.), Teoria e análises sobre implantação de políticas públicas no Brasil. Brasília, DF: Enap

Maneschy, M., Klavdahl, A. (2007). Redes de associações de grupos camponeses na Amazônia Oriental (Brasil): fontes de capital social? REDES Revista Hispana para el Análisis de Redes Sociales, 12(4), 5-19.

Marques, E. (2016). Governo, atores políticos e governança em políticas urbanas no Brasil e em São Paulo: conceitos para uma agenda de pesquisa futura. In T. Menicucci, J. Gontijo (Orgs.). Gestão e políticas públicas no cenário contemporâneo: tendências nacionais e internacionais. (pp. 71-99). Rio de Janeiro: Editora FIOCRUZ.

Marques, E. (2019). Notas sobre redes, Estado e políticas públicas. Cadernos de Saúde Pública, 35, 1-11.

Miller, H., Demir, T. (2007). "Policy communities”. In F. Fischer, G. Miller, M. Sidney (Orgs.). Handbook of public policy: theory, politics and methods. Boca Raton: CRC Press.

Moreira, V., Silveira, S. (2015). Indicadores de desempenho do Programa Minha Casa, Minha Vida: avaliação com base na satisfação dos beneficiários. Cadernos Gestão Pública e Cidadania, 20(66), 94-117.

Moreira, V., Silveira, S., Euclydes, F. (2018). Dinâmicas Locais na Implementação de Políticas Públicas: Análise do Programa Minha Casa, Minha Vida em Minas Gerais. Cadernos Gestão Pública e Cidadania, 23(75),170-193.

Pires, R., Lotta, G., Oliveira, V. (2018). Burocracia e políticas públicas no Brasil: interseções analíticas. 1a ed. Brasília: Ipea; Enap, (1), 422.

Pollitt, C. (2013). Context in public policy and management: The missing link? Cheltenham, UK: Edward Elgar Publishing.

Rua, M. (2012). Análise de políticaspúblicas: conceitos básicos. Dieese. Recuperado de projetos.diee-se.org.br/projetos/ SUPROF/Analisepoliticaspublicas.PDF

Sabatier, P., Weible, C. (2007). “The advocacy coalition: innovations and clarifications”. In P. Sabatier (Org.). Theories of the policy process.2a ed. Boulder, CO: Westview Press.

Schneider, V. (2013). Policy Networks and Relationalism. In 7th ECPR General Conference. Anais... Bordeaux, França.

Scott, J. (2009). Social Network Analysis: a handbook. London: Sage Publications.

Subirats, J., Knowepfel, P., Larrue, C., Varonne, F. (2012). Análisis y gestión de politicas públicas. (2a ed.). Barcelona: Planeta.

Stake. R. (2002). Case studies. In N. Denzin, Lincon, (orgs) Handbook of qualitative research. London: Sage, 435-454.

Stoker, G. (1998). Governance as theory: five propositions. International Social Science Journal, 50(155), 17-28.

Viana, R. (2019). Programa Minha Casa Minha Vida-Entidades e sem-tetos "não merecedores": a atuação da burocracia federal na diminuição de resistências locais. In R. Pires (Org.). Implementando Desigualdades Reprodução de Desigualdades na Implementação de Politicas Públicas. Rio de Janeiro: IPEA, (1), 1-730. 
Fillipe Maciel Euclydes, et al. Dinâmicas Relacionais na Implementação de Políticas Públicas: Anál...

Tatagiba, L., Teixeira, A. (2016). Efeitos combinados dos movimentos de moradia sobre os programas habitacionais autogestionários. Sociologia e Politica, 24(58), 85-102.

Tilly, C., Goodin, R. (2006). It depends. In R. Goodin, C. Tilly (Org.). The Oxford handbook of contextual political analysis. Oxford: Oxford University Press.

Zapelini, M. B., Lima, J. G., Guedes, M. C. (2017). Evolução da Política Habitacional no Brasil (1967-2014): Uma Análise de Equilíbrio Pontuado. Revista Interdisciplinar de Gestão Social, 6(3).

\section{Notas}

[i]Segundo Mineiro e Rodrigues (2012, p. 21), na coletânea organizada por Lago (2012), a autogestão habitacional é conceituada por "ações em que a construção de moradias (...) é produto do controle da gestão dos recursos públicos e da obra pelos movimentos populares, associações, entidades e cooperativas. Seria a própria comunidade gerindo o processo de produção da solução habitacional".

[ii] Optou-se por representar os variados indivíduos que participaram desse processo a partir das organizações, movimentos, instituições públicas e privadas dos quais fazem parte. Assim, os “atores” descritos nessa seção representam, na verdade, um número muito maior de indivíduos. 